\title{
EDITORIAL
}

\section{Shades of Grey: Radiopharmaceutical Chemistry in the 1990s and Beyond}

\author{
MICHAEL R. KILBOURN \\ Division of Nuclear Medicine, Department of Internal Medicine, The University of Michigan, \\ 3480 Kresge III, Ann Arbor, MI 48109-0552, U.S.A.
}

(Received 7 January 1992)

Science, like the universe itself, is ever expanding. The fields of biochemistry, physiology and pharmacology are rapidly growing, and radiopharmaceutical chemistry is no exception. In a recent Editorial Dr William C. Eckelman briefly reviewed the current status of radiopharmaceutical development (Eckelman, 1991). The ballots are out and returns are mixed. Radiopharmaceutical chemists have made great strides in the development and refinement of methods for radiochemical syntheses, but have made little impact on clinical Nuclear Medicine. Dr Eckelman ends his Editorial with a plaintive plea for more validation of radiotracers.

Dr Eckelman did not go far enough; radiopharmaceutical chemists need to be educated as to what are the important questions to which they should be devoting their time and talents. We do not need radiotracers to tell us where certain high affinity binding sites are in animal or human tissues; the fields of autoradiography and molecular biology are doing that just fine, with far greater resolution than we can ever hope for. It is not sufficient that new radiotracers are "validated" by a lack of specific binding after pharmacological pretreatments with massive amounts of cold drugs, or after severe neurochemical lesions in animal models, or in end-stage human disease. The answers we seek are not so black and white, but rather shades of grey. We need to develop sensitive in vivo measures of biochemical parameters which impact on the prevention or therapeutic treatment of human diseases. Nothing less.

In his Editorial, Bill Eckelman outlines three steps in radiotracer development. First, "develop a radiotracer that binds preferentially to a specific site". Second, "determine the sensitivity of the radiotracer to a change in biochemistry". Finally, "find a biochemical change as a function of a specific disease that matches that sensitivity". Dr Eckelman may have put the cart before the horse. The first step in a radiopharmaceutical development program should be to identify the relevant disease and the needed sensitivity (the percent change in any given parameter) which will be the focus of the study. Fortunately, more and more diseases are now being defined biochemically, with definitions of both the site and extent of an abnormal biochemical process. These data should be our ticket to the fun-house and our guide through the unknown. Admittedly, in many disease states the needed sensitivity may not be known; a good example is Parkinson's disease, where it is not known exactly what degree of change in the striatal dopaminergic system results in pregression from normal function to symptomatic disease (and will this imaginary boundary be the same for all subjects?). Even in these cases, however, it might be expected that the large scale changes present at end-stage disease will not be the primary target of in vivo studies, and development of radiopharmaceuticals with a matching all-or-none sensitivity might be of lesser interest.

One cannot disagree with Dr Eckelman that too little time, thought and effort is spent on the analysis of the sensitivity of a radiotracer measure, sometimes erroneously termed "validation". But just what is "validation"? It depends upon the question being asked. If one wishes to know the rate of loss of a specific binding site during the course of a neurodegenerative disease, a sensitivity to $5-10 \%$ changes in biochemistry might be required for medical utility. If one wishes, on the other hand, to differentiate between pathologies involving two optional but large scale changes in biochemistry, or simply the location of a large biochemical change, far less sensitivity might be perfectly acceptable.

So what kinds of sensitivity testing should be pursued? A favorite of many is the correlation between in vivo values, such as tissue ratios, $B_{\max }$, binding potential, volume of distribution or other parameter and in vitro measures of the same binding site or enzyme site densities as measured in different 
regions of an organ. Unfortunately, good in vitroin vivo correlations do not necessarily equate with successful clinical radiopharmaceuticals. We have, in the past few years prepared numerous potential PET radioligands for which adequate to quite good in vivo-in vitro correlations can be made (Haka and Kilbourn, 1989; Kilbourn et al., 1990a,b, 1991; Lee et al., 1991; Mulholland et al., 1992; Wieland et al., 1990; Rosenspire et al., 1990). However, in most cases the dynamic range of the in vivo measured values are only a fraction of the dynamic range for the in vitro values, and the sensitivity of such radiotracers to clinically relevant changes of in vivo biochemistry remains unknown. But are these radiotracers "validated" by the in vivo in vitro correlation, and if so, what are they useful for? Do the in vitro values even represent the functional range of such binding sites in the intact organism, and do the in vitro values represent the optimal "image" one might obtain from an in vivo study resplendent with secondary binding sites and generalized non-specific binding?

As an example, we have considerable experience with $\left[{ }^{18}\right.$ F]GBR 12909, which exhibits in vivo striatum/ cerebellum ratios (str/cer, a crude measure of specific binding) which do not even approach the values that might be calculated from the in vitro concentrations of dopamine uptake sites in these tissues (given that it is difficult to calculate a precise ratio, as there are no DA uptake sites in cerebellum). Some investigators are willing to explain these results through secondary binding to sigma receptors or a cytochrome P45OIIDl enzyme site (Niznik et al., 1990). Surprisingly, the cocaine analog CFT (WIN 35,428), also a dopamine uptake site radioligand, exhibits the exact same behavior: relatively poor in vivo str/cer ratios (<5) for ["C]CFT (Madras et al., 1991) despite exceptionally high values from the in vitro $\left[{ }^{3} \mathrm{H}\right] \mathrm{CFT}$ autoradiography in the same species (Kaufman et al., 1991). Some of this difference can be attributed to the problems of partial volume averaging in imaging of monkeys, but should the rest be attributed to CFT binding to other high affinity sites such as the P45OIID1 sites, for which cocaine has been reported to have a high (74 nM) affinity (Tyndale et al., 1991), or possibly also the sigma receptor? Given the long list of compound types which show affinity for the sigma receptor (Koe et al., 1991), maybe the question should be reversed; what does not bind to the sigma receptor? And, really, does it matter? Even more to the point, if we are to utilize a radiotracer to evaluate a specific binding site in specific tissue regions, should we even be concerned with the behavior of that radioligand in tissues or regions uninvolved in the physiology or pathology in question? As one begins to ponder these questions, "validation" by comparison of in vivo and in vitro regional organ distributions seems incomplete.

The second standard method of "validation" is determining the dose-response curve of radioligand binding in animals, using competition for sites by doses of the identical or pharmacologically equivalent but structurally different drugs. Is this sufficient? Such studies demonstrate that measured values of in vivo binding sites can be reduced by competing drugs, but are such pharmacological challenges the equivalent of the functional changes evidenced during a disease process? Probably not; biochemistry is very complex, and it is almost inconceivable that changes in one aspect such as a number of binding sites or enzyme molecules are not accompanied by other changes in biochemistry. Proving that a drug treatment "mimics" a disease is challenging, and one must question whether a dose-response curve is a "validation" of the usefulness of the radiotracer in the intended disease.

Should tracers be "validated" in animal models of human diseases, or even better, through clinical trials? The last is a poor alternative; the costs and ethics of radiotracer evaluation in humans can be prohibitive. What about animal models? This may be an under-utilized methodology in radiopharmaceutical development, as there are certainly a plethora of lesion (Conn, 1991), behavioral and genetic animal models for human diseases, even for such diseases as senile dementia (Lal and Forster, 1991). In the same issue which held Dr Eckelman's Editorial, we published one of our attempts in this area, utilizing the degeneration and subsequent regeneration of dopaminergic terminals in MPTP-treated mice as what might be envisioned as a "reverse" model of Parkinson's disease (Kilbourn et al., 1991). Relatively crude measures of in vivo specific binding of $\left[{ }^{18} \mathrm{~F}\right] \mathrm{GBR}$ 13119 (a dopamine uptake blocker and putative neuronal marker) in mouse striatum increased with recovery of the animals. Remarkable correlations with published recoveries of tissue dopamine $\left(r^{2}=0.98\right)$ and tyrosine hydroxylase enzymatic activity (TH: $r^{2}=0.99$ ) measured in vitro for the same animal model could be made (Fig. 1.) (Donnan et al., 1987; Nishi et al., 1989), although such were not reported in that publication. Is this a more proper way of "validation"? The discerning rcader will notc that the dynamic range for $\left[{ }^{18} \mathrm{~F}\right] \mathrm{GBR} 13119$ binding is larger than the dynamic range for $\mathrm{TH}$ enzymatic activity, but less than the dynamic range for endogenous dopamine levels. Which are the proper in vitro data to use in such correlations, and which correlation is correct for modeling Parkinson's disease in humans? Which in vitro measure-tyrosine hydroxylase, which is perhaps a measure of surviving neurons, or dopamine, which might be a better measure of the functional status of the surviving neurons-would be important in the development (and perhaps evaluation through in vivo PET studies) of therapeutic drug strategies for prevention or amelioration of Parkinsonian symptoms? As Dr Eckelman points out, even such encouraging results in animals can be hard to translate to clinical efficacy, but perhaps more such efforts should complement current efforts at radiotracer "validation". 

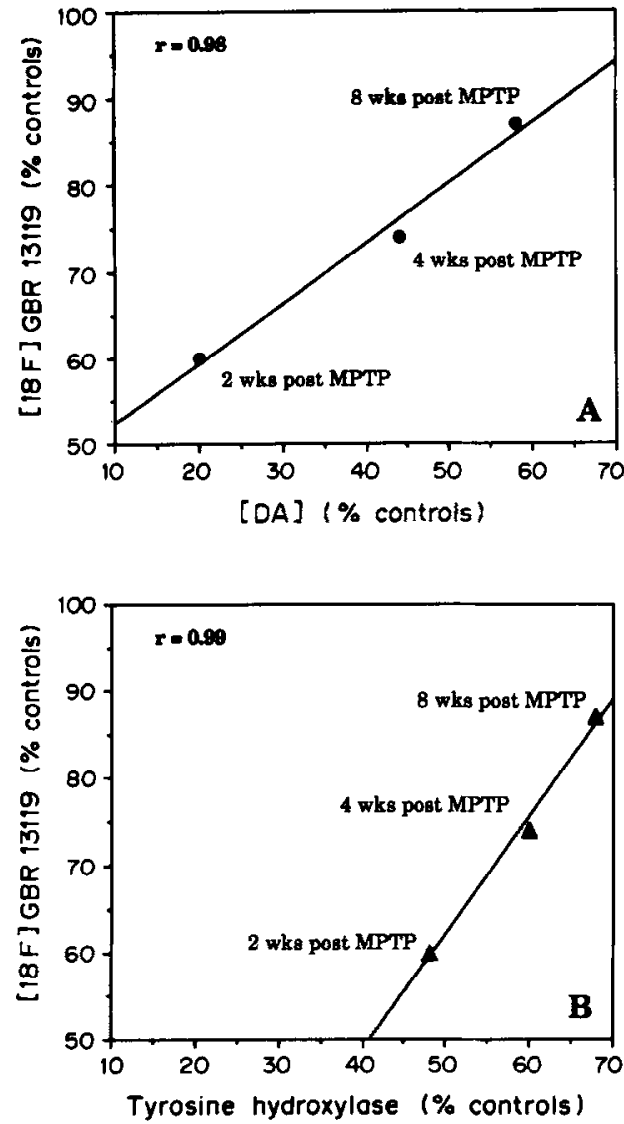

Fig. 1. Correlations of in vivo specific binding of $\left[{ }^{18} \mathrm{~F}\right] \mathrm{GBR}$ 13119 with in vitro measures of endogenous dopamine concentrations (A) and tyrosine hydroxylase enzymatic activities (B) in the striatum of mice at selected times following systemic MPTP treatment. In vivo data from Kilbourn et al. (1991) and in vitro data from Donnan et al. (1987) and Nishi et al. (1989).

Development of new radiopharmaceuticals has become, if anything, even more complicated and challenging: neurochemistry, pharmacology and molecular biology have spawned a whole new and sometimes bewildering neurochemical landscape. There are five muscarinic receptors, and at least five dopamine receptors; who knows how many subtypes of subtypes of serotonin receptor may eventually surface. Glutamate pharmacology, once neatly wrapped up as NMDA, kainate and quisqualate receptors, is exploding: there is at least one new receptor type not linked to an ion channel (metabotropic receptor), and possibly multiple subtypes of each of these receptor types (Aizawa et al., 1991; Vecil et al., 1991; Sakurai et al., 1991) There may be multiple forms of tyrosine hydroxylase; the functional significance of this finding still eludes us (Melchitz et al., 1991). Armed only with a radiochemical, an imaging device and a pharmacokinetic model (Carson, 1991), are we too presumptuous to think we can ever figure out nature's complexities?

Do we make too many new radiochemicals with too little evaluation of their applicability? Perhaps; certainly a disproportionate share of the resources is devoted to synthesis of new variants of radiopharmaceuticals that have not been fully evaluated in the first place. But we may also analyze ourselves into a corner, and suffer paralysis of both thought and action. The synthesis of new radiotracers and their evaluation through in vivo-in vitro correlations, dose-response analyses and animal models will continue as our route to new clinical radiopharmaceuticals. So until such time as we have all of the answers on a theoretical basis, much has been and will continue to be learned from the experimental approach.

Acknowledgement - This work was supported by USPHS grants NS15655 and MH47611.

\section{References}

Aizawa H., Kwak S., Ishida M. and Shinozaki H. (1991) Pharmacological evidence suggesting multiplicity of kainate receptors in the rat central nervous system. Soc. Neurosci. Abstr. 17, 1538.

Carson R. E. (1991) The development and application of mathematical models in nuclear medicine. J. Nucl. Med. 32, 2206.

Conn M. P. (1991) Lesions and transplantation. In Methods in Neuroscience, Vol. 7. Academic Press, New York.

Donnan G. A., Kaczmarczyk S. J., McKenzie J. S., Rowe P. J., Kalnins R. M. and Mendelsohn F. A. O. (1987) Regional and temporal effects of 1-methyl-4-phenyl1,2,3,6-tetrahydropyridine on dopamine uptake sites in mouse brain. J. Neurol. Sci. 81, 261.

Eckelman W. C. (1991) The status of radiopharmaceutical research. Nucl. Med. Biol. 18, iii.

Haka M. S. and Kilbourn M. R. (1989) Synthesis and regional brain distribution of $\left[{ }^{11} \mathrm{C}\right]$ nisoxetine, a norepinephrine uptake inhibitor. Nucl. Med. Biol. 16, 771.

Kaufman M. J., Spealman R. D. and Madras B. K. (1991) Distribution of cocaine recognition sites in monkey brain: I. In vitro autoradiography with $\left[{ }^{3} \mathrm{H}\right] \mathrm{CFT}$. Synapse 9, 177.

Kilbourn M. R., Mulholland G. K., Sherman P. S, and Pisani T. (1991) In vivo binding of the dopamine uptake inhibitor $\left[{ }^{18} \mathrm{~F}\right]$ GBR 13119 in MPTP-treated C57BL/6 mice. Nucl. Med. Biol. 18, 803.

Kilbourn M. R., Pavia M. R. and Gregor V. E. (1990a) Synthesis of fluorine-18 labelled GABA uptake inhibitors. Appl. Radiat. Isot. 41, 823.

Kilbourn M. R., Jung Y.-W., Haka M. S., Gildersleeve D. L., Kuhl D. E. and Wieland D. M. (1990b) Mouse brain distribution of a carbon-11 labeled vesamicol derivative: presynaptic marker of cholinergic neurons. Life Sci. 47, 1955.

Koe B. K., Fox C. B. and Lebel L. A. (1991) Structural classes of compounds with potent affinity for brain sigma binding sites. Soc. Neurosci. Abstr. 17, 332.

Lal H. and Forster M. J. (1991) Autoimmune mice as models for discovery of drugs against age-related dementia. Drug Dev. Res. 24, 1.

Lee K. S., Frey K. A., Koeppe R. A., Mulholland G. K., Kilbourn M. R. and Kuhl D. E. (1991) In vivo quantification of muscarinic cholinergic receptors in human aging: positron tomography suggests preferential cortical decline. J. Cereb. Bld Flow Metab. 11, S790.

Madras B. K., Fahey M. A., Kaufman M. J., Spealman R. D., Schumacher J., Isacson O., Brownell A. L., Brownell G. L. and Elmaleh D. R. (1991) Cocaine 
receptor probes in human and nonhuman primate brain: in vitro characterization and in vivo imaging. Soc. Neurosci. Abstr. 17, 190.

Melchitz D. S., Scolieri M. J., Haycock J. W. and Lewis D. A. (1991) Expression of different forms of tyrosine hydroxylase in monkey and human brain. Soc. Neurosci. Abstr. 17, 980.

Mulholland G. K., Otto C. A., Jewett D. M., Kilbourn M. R., Koeppe R. A., Sherman P. S., Petry N. A., Carey J. A., Atkinson E. R., Archer S., Frey K. A. and Kuhl D. E. (1992) Synthesis, biodistribution, dosimetry, metabolism and monkey PET studies of carbon-11 labeled ( + - $-2 \alpha$-tropanyl benzilate, a central muscarinic receptor imaging agent. J. Nucl. Med. 33, 423.

Nishi K., Kondo T. and Narabayashi H. (1989) Differences in recovery patters of striatal dopamine content, tyrosine hydroxylase activity and total biopterin content after 1-methyl-4-phenyl-1,2,3,6-tetrahydropyridine (MPTP) administration: a comparison of young and older mice. Brain Res. 489, 157.

Niznik H. B., Tyndale R. F., Sallee F. R., Gonzalez F. J., Hardwick J. P., Inaba T. and Kalow W. (1990) Archs Biochem. 276, 424.
Rosenspire K. C., Haka M. S., Van Dort M. E., Jewett D. M., Gildersleeve D. L., Schwaiger M. and Wieland D. M. (1990) Synthesis and preliminary evaluation of carbon- 11 meta-hydroxyephedrine: a false neurotransmitter for heart neuronal imaging. J. Nucl. Med. 31, 1328.

Sakurai S. Y., Penney J. B. and Young A. B. (1991) Regionally distinct NMDA receptor subtypes distinguished by [ $\left.{ }^{3} \mathrm{H}\right] \mathrm{MK}-801$ binding. Soc. Neurosci, Abstr. 17, 1534.

Tyndale R. F., Sunahara R., Inaba T., Kalow W., Gonzalez F. J. and Niznik H. B. (1991) Neuronal cytochrome P450IIDI (Debrisoquine/sparteine-type): potent inhibition of activity by (-)-cocaine and nucleotide sequence identity to human hepatic P450 gene CYP2D6. Molec. Pharm. 40, 63.

Vecil G. G., Li P. P. and Warsh J. J. (1991) Evidence for metabotropic excitatory amino acid receptor heterogeneity: developmental and brain regional studies. Soc. Neurosci. Abstr. 17, 70.

Wieland D. M., Rosenspire K. C., Hutchins G. D., Van Dort M., Rothley J. M., Mislankar S. G., Lee H. T., Massin C. C., Gildersleeve D. L., Sherman P. S. and Schwaiger M. (1990) Neuronal mapping of the heart with 6- $\left[{ }^{18}\right.$ F $]$ fluorometaraminol. J. Med. Chem. 33, 956. 